\title{
A NARRATIVA DESARMADA DE HERBERT DANIEL
}

Felipe Areda (UFSC)

Resumo: Este trabalho se debruça sobre a noção de "narrativa desarmada", a partir da qual o escritor homossexual brasileiro Herbert Daniel (1946 - 1992) apresenta seu livro Meu Corpo Daria um Romance, de 1984. Investiga como, ao apresentar seu corpo como terreno tradutório, sua narrativa se esforça para desconstruir os mecanismos epistemológicos da homofobia.

Palavras-chave: Herbert Daniel, Narrativa Desarmada, Violência, Homofobia, Corpo.

Abstract: This paper has addressed the notion of "disarming narrative", the starting point for Brazilian homosexual writer Herbert Daniel's (1946 -1992) book - Meu Corpo Daria Um Romance from 1984. We have investigated how, by means of presenting his body as a field of translation, the author attempted to deconstruct the epistemological mechanisms of homophobia.

Key Words: Herbert Daniel, Disarming Narrative, Violence, Homophobia, Embodiment.

Somente quem soubesse considerar o próprio passado como fruto da coação e da necessidade seria capaz de fazê-lo, em cada presente, valioso ao máximo para si. Pois aquilo que alguém viveu é, no melhor dos casos, comparável à bela figura à qual, em transportes, foram quebrados todos os membros, e que agora nada mais oferece a não ser o bloco precioso a partir do qual ele tem de esculpir a imagem de seu futuro. (Benjamin, 2012, p. 40) 


\section{O CORPO SEM FRONTEIRAS E LIMITES}

O livro Meu Corpo Daria um Romance de Herbert Daniel, publicado em 1984 pela editora Rocco no Rio de Janeiro, se apresenta como uma narrativa desarmada (DANIEL, 1984). Seu enredo se dá em torno de uma cena de 11 minutos, nos quais Daniel entra em um ônibus na madrugada de Copacabana logo após despedir-se com um beijo em seu amigo e namorado. A narrativa lida com a vivência da homofobia nos minutos da duração da viagem dentro desse ônibus, no qual Daniel recebe os olhares e o escárnio dos outros passageiros. É diante da necessidade de uma resposta à violência que a narrativa se tece. Perante esses onze minutos, o livro é arquitetado em onze capítulos, apresentados pelo autor como partes do corpo fragmentadas pela violência. São essas: orelhas (a qual não é um capítulo, mas as abas laterais, as orelhas, do livro), buracos da cabeça, genitália, glândulas, peles e anexos, extremidades do aparelho digestivo, aparelho circulatório e sangue, órgãos da fonação, órgãos sentidos, aparelho locomotor e solidariedade.

O livro é arquitetado em três eixos: Matéria, Dissertação e Falhas. Na matéria, o autor apresenta o relato dos materiais vividos - a memória. Na dissertação, são apresentados 
contos, crônicas ou fábulas, que articulam sua trajetória ao que Daniel chama de dejetos do imaginário - a ficção. As Falhas - os fragmentos - estão presentes em lista no undécimo capítulo ou como ausências marcadas por asteriscos ao longo de toda tessitura do texto.

A memória não é apresentada por Daniel como recordação objetiva do vivido. Ela não recapitula apenas o vivido, mas a memória das lembranças. Daniel não reivindica, portanto, uma objetividade autobiográfica, sobre a qual já fazia a crítica em sua obra Passagem para o Próximo Sonho, de 1982, a qual definiu como um romance autocrítico (DANIEL, 1982). Prefere evocar a fluidez contaminadora e criativa do que chama de biofragâncias. A noção de fragrância aponta para uma noção de memória que é menos aquela evocada por filmes e álbuns de fotografia e mais a imagem erótica da memória presente nos perfumes do corpo amado que, apesar dos banhos, impregnam nossa própria corporeidade, evocando - e invocando - mais do que a memória do corpo do outro, a memória do nosso corpo em mistura com o outro. Nesse movimento, Daniel aponta para o caráter revelador inesperado da memória, chamando-a também de bioflagrantes.

A ficção é apresentada por Daniel não apenas como a criação de personagens que apresentam estórias paralelas à 
sua trazendo elementos para dissertar sobre a subjetividade, a ficção é apresentada como mecanismo constituidor de qualquer subjetividade. Nesse sentido, a Dissertação não é apenas uma ficção, mas um dissertar sobre o caráter ficcional da vida. Meu Corpo Daria um Romance é uma narrativa biograficcional, na qual se trata não apenas de uma ficcional escrita da vida, mas de uma escrita que revela o caráter ficcional da produção das formas de vida.

As falhas - "zonas de vácuo, vazios ou ausências" (DANIEL, 1984 , p. 10) - marcam rupturas no relato, manifestações de ausências na narrativa. São menos da ordem do silêncio e mais do inaudível e do inefável. Não são pausas, são quebras. Não são cisões, são cicatrizes. Daniel apresenta e enfrenta em linguagem sua própria incapacidade de descrição em um contexto no qual a violência cala, obriga a gritar e dá os termos do próprio grito. Por conseguinte, o autor se esforça em introduzir uma sequência de ausências no dito, incidindo na estrutura de narrativa e abrindo a capacidade de narrar e de apresentar a irrupção do inenarrável. Daniel associa a presença das falhas com a letra $\mathrm{H}$, letra sem som, mas que introduzida em uma estrutura a altera: fal(h)a. A letra $H$, letra inicial de seu nome, também representa a incidência do seu corpo na linguagem e na transformação 
de sua estrutura. "Sendo o H uma letra muda," - diz Daniel "como na habertura do meu herbert, sua hacentuação haqui haltera ha hestrutura: hecoa palatizando, na palavra falha, a letra L, como a do meu finaL do meu danieL: éle ou êle." (DANIEL, 1984, p. 10).

Herbert Daniel é um nome composto de seu nome de registro de nascimento - Herbert - em dezembro de 1946 sob o signo de Sagitário (cuja representação em um desenho está na capa de seu livro, sendo a astrologia constante referência em sua obra, em especial no livro Alegres e Irresponsáveis Abacaxis Americanos (DANIEL, 1987) e por um dos seus nomes utilizados na guerrilha clandestina de oposição e sobrevivência ao regime militar no Brasil - Daniel. O autor ingressou na militância de oposição ao Regime Militar no Brasil em 1967 na Organização Revolucionária Marxista Política Operária (Polop), participando depois do Comando de Libertação Nacional (Colina) e, por último, da Vanguarda Popular Revolucionária (VPR). Acompanhou também a criação do foco guerrilheiro do Vale do Ribeira, em 1969, e participou em 1970 dos sequestros do embaixador alemão Ehrenfried von Holleben e do suíço Giovanni Bucher. Sendo um dos militantes mais procurados pela força repressiva no Brasil, exilou-se na Europa em 1974. Não foi anistiado pela lei no 6.683 de 1979, a Lei da Anistia, e só 
retorna ao Brasil em 1981 após a prescrição de suas acusações.

Em seu livro Passagem para o próximo sonho de 1982, Daniel se debruçou sobre as relações entre três exílios: o desterro da militância clandestina, o asilo europeu em fuga da repressão militar brasileira e o degredo da homossexualidade. No Meu Corpo Daria um Romance investiga, a partir da memória, da ficção e dos fragmentos, as tensões entre o corpo desejante homossexual e sua fuga corporal na afirmação do sujeito militante com disciplina revolucionária - tensão que repercutiu em sete anos sem relações sexuais vivenciando a culpa da noção de sexo. Essas reflexões são motivadas por meio do acontecimento rememorado em todos os capítulos do livro. Ao entrar no ônibus, após um beijo apaixonado de despedida e iniciada a violência pelos outros passageiros do transporte público, a personagem se refugia em um assento próximo a dois homens, um com camisa com a estrela símbolo do Partido dos Trabalhadores (PT) e o outro com uma contendo a inscrição da palavra Solidarność, da federação sindical polonesa fundada em 1980. Ali presumia companheiros de um projeto de sociedade - Daniel foi militante do PT -, no entanto, deles se tornou alvo de mais violência.

É para esses dois companheiros que o livro de Daniel se 
direciona. Trata-se de um livro sobre a violência homofóbica escrito para dois perpetradores - perpetuadores - dessa violência. Ao longo de cada abertura de capítulo, o autor se pergunta sobre como responder à violência: "Teme? Reage? Cala? Foge? Argumenta? Responde? Interroga? Suporta?" (DANIEL, 1984, orelha). O livro é para Daniel o que ele chama de literatura de antecipação. Antecipação não se refere a uma figura de retórica de refutação prévia de oposições possíveis, mas de uma literatura que diz de um projeto - de vida, de corpo, de prazer e de solidariedade - e, portanto, o antecipa, bem como uma narrativa que se produz diante do outro - semelhante e dessemelhante. Como diz o autor: "Antecipar: dizer vai ser. Ou: ante si par... ou ímpar. Ante mim o par que és, orelha e boca vossas, dialogo nosso; o par que seremos em outro no ímpar que somos ante o si próprio" (DANIEL, 1984, orelha).

Com o escopo desse diálogo, o livro não é uma defesa ou justificativa da normalidade da homossexualidade. Não é também uma reivindicação de respeito às especialidades eróticas de cidadãos homossexuais. A necessidade de justificar é, para Herbert Daniel, parte do regime de opressão - "Jamais vivemos: criamos álibis" (DANIEL, 1984, p.50). Ao partir de suas memórias para apresentar a rejeição corporal estruturada pela 
categoria sexo, o autor não pretende falar de um sofrimento concernente apenas aos homossexuais. Ao olhar para seu sexo, investiga um exemplo de uma política geral: a ideologia do massacre. "Eu não vivo um caso meu," - diz Daniel - "mas suporto uma política geral, como exemplo exemplar, ao mesmo tempo um indício de futuras expiações, que quando vierem, já será demasiado tarde para suportar" (DANIEL, 1984, p.145).

Herbert Daniel, ao entrar no ônibus, tem pela ideologia do massacre sua identidade produzida na diferenciação - vira o viado, o outro, um caso. Como diz o autor: "Virei caso: este um, indicado por um demonstrativo e por uma indeterminação. Como se eu não fosse um projeto múltiplo, mas apenas um delírio individual, um sintoma. Como se eu não fosse, como todos, uma possibilidade de combate." (DANIEL, 1984, p.270). Contra essa ideologia, Daniel apresenta seu corpo como lugar de tradução das zonas intersticiais de sexo, classe, raça, geração, desejo, estética e conformação corporal. As cisões produzem cicatrizes e essas - fragmentos e falhas - são possibilidades de conexão. O ônibus, com vários homens trabalhadores e uma única mulher negra trabalhadora, na madrugada de corpos explorados e expropriados pelo trabalho, pelo medo e pela necessidade de se preservar e oprimir, é o território de tensão na qual 
a ideologia do massacre afirma o caráter minoritário de Daniel, contra a qual ele responde com uma literatura de antecipação: “Não, eu não queria compreensão, nem dó, nem piedade. Nem mesmo apoio. Não sou EU! Somos nós, nesta jaula que atravessa a noite, a cidade, a ideologia do massacre" (DANIEL, 1984, p.85).

O autor afirma que noções de corpo são noções de política (DANIEL, 1984, p.09). A ideologia do massacre opera pela produção de noções de corpos, ela é "a ideologia de um corpo de leis" (DANIEL, 1984, p.275). Essa ideologia estabelece um "mito do corpo" (DANIEL, 1984, p.37) a partir da distinção entre dentro e fora que engendra a rejeição corporal - organizada na categoria sexo. Como diz sobre si: "Ele queria na parte de dentro ser bonito e amar - amar normal" (DANIEL, 1984, p.37). Contudo, continua Daniel: "Era uma ilusão. Ninguém tem um dentro e um fora. O humano não admite nem fronteira, nem limite. É um descontínuo que vai de um a outro e volta ao porão do um" (DANIEL, 1984, p.37). Contra essa ideologia que estabelece o corpo como entidade discreta, estruturando noções de visibilidade/ invisibilidade, fora/dentro e outro/eu, o corpo é por Herbert Daniel defendido como elemento descontínuo de conexão, relembrando a crítica artaudiana da separação entre 
simbólico e material, metafísica e física ${ }^{1}$. Por esse motivo, todo capítulo começa com a expressão "corpo a corpo". O pronome do "meu corpo" presente no título, portanto, não pode ser entendido como significador possessivo de uma unidade discreta. Conforme alerta o autor: "Digo meu sem fazer do possessivo uma marca de propriedade, posse ou qualidade. Digo meu como diria algo de mim a mim - sem dentro e fora" (DANIEL, 1984, orelha).

\section{DIANTE DA EPISTEMOLOGIA DA VIOLÊNCIA}

Assumindo o corpo como elemento de conexão e antecipação, Herbert Daniel inicia seu livro na orelha rompendo com uma perspectiva epistemológica centrada na visão, como marcador da distinção de sujeito e objeto, metáfora privilegiada do conhecimento ${ }^{2}$ e operador da violência homofóbica - "Insuportável é o olhar do outro que te torna outro e grotesco. Insuportável é o olhar que te cerca no descampado da calamidade da tua diferença. Insuportável é o olhar da inquisição" (DANIEL, 1984, p.50). Durante seu livro, Daniel se vê diante dos olhares que operam a epistemologia da violência: olhares cínicos, clínicos,

\footnotetext{
1 Na epígrafe do livro, Daniel cita Antonin Artaud: "Não há dentro interior, nada de espírito, / exterior não há, nem consciência; / há só o corpo que como tal é visto / mesmo quando falha a vista / do olho que o vê. / Tal corpo é tal fato. / Eu." (Apud DANIEL, 1982, p. 5)

2 Para uma reflexão sobre a persistência da visão como metáfora privilegiada do conhecimento imparcial e uma defesa da parcialidade objetiva da visão, ver Haraway, 1995.
} 
diagnósticos, inquisidores, dissecadores e tribunalescos. São os olhares da análise, que tentam dividir o indivisível - o corpo, essa "praça do prazer irregular, desuniforme e íntegra" (DANIEL, 1984, orelha). A orelha é marca de uma narrativa que se inicia com uma abertura epistemológica, de um conhecimento que toma a abertura e a conexão como princípio, método e objetivo. Como afirma Daniel:

(...) este é um ensaio biograficcional, que começa nesta orelha, deste órgão-zero de um corpo sobre um corpo que não se quer parcelado, ou de partido, mas quer dar o sentido geral de uma partilha.

Nunca coisa órgão. O meu que faz um corpo é o contágio do corpo a corpo.

Nunca dividido; compartilhado.

Por isso, no corpo a corpo, começo neste dito órgão zero, orelha, princípio do contágio, donde este livro diz, vos escutando. (DANIEL, 1984, orelha).

A epistemologia defendida por Daniel recusa a noção de razão - em Passagem para próximo sonho o autor já defendia como forma de manter a lucidez não tentar "ter razão" na escrita (1982, p. 35) -, apostando na articulação entre consciência e emoção em uma perspectiva de erotização do pensamento, para a qual é central a noção de contágio. Por esse motivo, em face da noção ideológica de análise, o autor afirma a noção erótica de fluições teóricas. 
Pensar não é só - ou nunca é racionalizar. É sim uma forma de sentir, tanto quanto a sensibilidade é uma apreensão pensada. Não consigo distinguir excludentemente consciência e emoção, teoria e coração. São qualidades distintas do ato de pensar. Eu penso assim, quer dizer, com fluições teóricas. O ria-te. Ria o tê (de tesão). (DANIEL, 1984, p. 147)

Herbert Daniel inicia sua obra-corpo desde um posicionamento de abertura epistemológica, propondo uma escrita que começa escutando e a produção de fluições teóricas que partem do diálogo e vão em direção a ele. O diálogo é apresentado por Daniel como noção chave de leitura da obra. O diálogo, para o autor, é diretamente associado à noção de contaminação, como mecanismo que rompe a ideologia das distinções corporais enfrentando as fundamentações epistemológicas da violência as quais são as fundações da constituição do sexo.

Segundo Michel Foucault (1988), a sexualidade foi construída como dispositivo no século XVII em um processo que conectou de modo inseparável conhecimento e sexo. As sociedades modernas colocaram o sexo no centro da pressão epistemológica do questionamento sobre a verdade do sujeito. Como afirma Foucault: "o que é próprio das sociedades modernas não é terem condenado o sexo a permanecer na obscuridade, mas sim o terem-se devotado a 
falar dele sempre, valorizando-o como segredo" (FOUCAULT, 1988, p. 36). A noção de segredo - e adjetivar esse segredo como sexual é redundante, já que a noção de sexo só existe operando a noção de segredo e a noção de segredo se tornou na modernidade uma noção sexual - é engendrada por uma série de dicotomias, sendo centrais as oposições de dentro/fora e intervisibilidade/visibilidade. Para Eve Kosofsky Sedgwick (2007), essas oposições, bem como as noções de privado/público e segredo/revelação, são operadas pela noção de "armário" e esse tem sido o dispositivo regulador da vida de gueis e lésbicas ${ }^{3}$. Segundo Sedgwick, a violência do dispositivo da sexualidade opera como uma epistemologia. Dentro dessa, o desejo homossexual é constituído dentro de um conjunto de regulações contraditórias, estabelecendo o desejo homossexual com um posicionamento cognitivo particular - alvo do conhecimento e cujo acesso ao conhecimento é interdito. Essa perspectiva está sintetizada na frase de Lorde Alfred Douglas: "Eu sou o Amor que não ousa dizer seu nome" (DOUGLAS, 1894, p. 28 Apud SEDGWICK, 2007).

Herbert Daniel enfrenta o desafio de ousar dizer o nome - ou romance - desse Amor. No entanto, sabe que

3 Para Sedgwick a crise específica da posição epistemológica homossexual tem impacto em outros pares centrais na organização da vida cultural moderna, tais como: "masculino/ feminino, maioria/minoria, inocência/iniciação, natural/artificial, novo/velho, crescimento/ decadência, urbano/provinciano, saúde/doença, mesmo/diferente, cognição/paranóia, arte/ kitsch, sinceridade/ sentimentalidade e voluntariedade/dependência." (2007, p. 28-29). 
afirmar esse desejo pode significar simplesmente operar uma epistemologia que perpetua os mesmos mecanismos dicotômicos de invisibilidade/visibilidade e minoria/maioria. Por esse motivo, faz de sua narrativa uma investigação epistemológica da ruptura daquilo que Monique Wittig (1992) chamou de Pensamento Hétero, um pensamento que se estrutura a partir de um regime político que se engendra na produção de diferenças. Na obra de Herbert Daniel vislumbramos, portanto, uma investigação das possibilidades de ruptura da epistemologia que é operada pela violência no regime político heterossexual, apontando para seus mecanismos reguladores e as possibilidades de seu enfrentamento. Dizer o nome - ou nomes - desse amor é, portanto, um ato político. Como diz Daniel: "Precisamos denominar nosso prazer e nomear - dominando - o poder com todos os palavrões necessários" (DANIEL, 1984, p. 231).

A obra-corpo de Daniel nos possibilita uma investigação da repercussão epistemológica da perspectiva homossexual, estudando a reverberação das experiências de campos de desejo, afetos e relações amorosas na produção de análises sociais, políticas, éticas, estéticas, antropológicas e filosóficas. Como a experiência de desejos, identidades e relações afetivas dissonantes da ideologia de um corpo de leis organiza 
e desorganiza nosso olhar - e ouvidos - sobre o mundo? Essa pergunta conecta a obra de Daniel com a produção do feminismo perspectivista não-relativista (Conf. HARDING, 1986; HARTSTOCK, 1986; e HARAWAY, 1995) ao apontar para uma vantagem epistêmica na escrita a partir da localização, do enraizamento e da parcialidade da experiência das pessoas subjugadas. "Ao mesmo tempo percebia, sem olhar, porém enxergando tudo deles, como só é possível ao observador observar.", diz Daniel (1984, p. 84) defronte dos olhares homofóbicos. Meu Corpo Daria um Romance revela sobre a homofobia desde a perspectiva de quem é por ela escarnido.

Não obstante, não se trata de uma perspectiva desde uma identidade homossexual, ampla e genérica. Trata-se de um corpo homossexual e corpo deve ser entendido aqui como "unidade contraditória do espaço social" (DANIEL, 1984, orelha). Daniel apresenta as contradições dos desejos dentro dos espaços de vivência homoerótica reais, expondo que esses não são livres da estruturação pelo machismo, misoginia, racismo, classismo, padrões estéticos, gordofobia - pela ideologia do massacre.

\section{O CORPO COMO TERRITÓRIO DE TRADUÇÃO}

A experiência da clandestinidade - no corpo, no desejo, no sexo, na raça, na nação - é apresentada por Herbert Daniel como posição de liminaridade, como território 
fronteiriço de deslocamento. O romance fragmentado apresenta o corpo como terreno de conflitos de definições e de linguagem, entrelugar de tensões de tramas e projetos, fronteiras que são zonas de contato e de contágio. Por esse motivo, a obra de Daniel tece o que Walter Mignolo (2003) chamou de "pensamento liminar", fazendo do Meu Corpo Daria um Romance, ao utilizar práticas de leitura e escrita como estratégias de luta contra o poder, um projeto de "linguajamento" (MIGNOLO, 2003, p. 309). No linguajamento de Daniel, o corpo é instrumento da leitura e da escrita.

Posso contar todo um romance de conflitos entre minhas vontades e meu desejo, ou seja, um romance com uma tessitura política - que exclui, portanto, uma trama regular e linear. Posso contar um romance que apresenta capacidades em confronto com poderes, exercícios físicos, através do meu corpo. (DANIEL, 1984. p. 277)

Rompendo com a linearidade e regularidade, Herbert Daniel tece uma narrativa desde a homossexualidade em mundo macho, desde a clandestinidade em um regime militar, desde o exílio de sua nação em uma luta para revolucioná-la, desde sua pele mulata $^{4}$ em mundo racista,

4 O termo "mulato", pela sua origem na palavra mula, tem seu caráter ofensivo, desumanizador e depreciador denunciado pelo movimento negro brasileiro contemporâneo. Ainda que concorde com a recusa do uso desse termo no cotidiano, o utilizo nessa narrativa por ele ser apropriado como auto-identificação por Herbert Daniel. O autor, filho de pai negro, discorre sobre como o racismo é parte da ideologia de rejeição corporal que apaga a ancestralidade negra e a negritude da ancestralidade. $O$ racismo atua no espaço familiar afetando a capacidade 
desde sua feiura em um mercado corporal da sedução, desde o amor em uma ideologia do massacre.

É importante ressaltar que a assimetria de poder dentro da epistemologia por meio da qual a violência opera é, conforme nos apresenta Daniel - experimentada nas contradições da corporeidade dos sujeitos em sua circulação cotidiana pelo mundo. Dentro do ônibus em que entra Herbert Daniel, durante a madrugada de corpos exaustos pela exploração do trabalho, há apenas uma mulher negra. Todos os homens o olham - "cínicos, clínicos, diagnósticos" (DANIEL, 1984, p. 14) -, menos essa mulher. Como descreve Daniel, a mulher mantinha os olhos fechados fingindo dormir e abstraindo um corpo que precisava passar despercebido naquela madrugada: "Ela não me olhou: que dormitava, embora (...) guardasse abertos olhos assustados no tangente temor de ser trabalhadora e negra e mulher e publicamente transportada na companhia de homens nesta hora de machos e putas" (DANIEL, 1984, p.14). Daniel, embora não finja dormir perante aqueles que o miram com inquisidor olhar, não pode devolver a mirada. No ônibus, encena-se uma assimetria entre aqueles que

de reconhecimento e autorreconhecimento e faz com que sua cor mulata seja experimentada em projeto familiar de embranquecimento que garante "a moralidade da respeitabilidade de uma cor difusa." (DANIEL, 1984, p. 99). Por esse motivo, Daniel só percebe que seu pai é um homem negro quando já adulto e não "moreninho" como a ideologia familiar o ensinara. No racismo brasileiro, há cores que não ousam dizer seu nome. 
podem olhar e as que precisam cautelosamente manter as pálpebras cerradas, entre os que podem mirar e os que precisam abaixar os olhos. A partir da concretude de como as posições hierárquicas se estruturam como posições de conhecimento, Herbert Daniel apresenta a visão como o sentido, metáfora e instrumento de uma epistemologia que opera por distinções e as cria. Contra esse ordenamento, o diálogo precisa nascer da escuta, enquanto mecanismo de abertura epistemológica e potência de desmoronamento do medo e do ódio. Como diz Daniel sobre seus homofóbicos companheiros - aos quais o livro é destinado:

Eu Ihes desejava a orelha - órgão zero - para dizer o que se passava comigo e conosco. Eu queria Ihes explicar o sexo - e não só o meu - com tudo que fosse pertinente ao amor e não apenas ao constrangimento genital das regras da vulgarização do amor. Eu queria lhes oferecer o corpo - e não só o meu - com tudo que fosse pertinente à busca da felicidade e não apenas à ejaculação de promessas definindo a felicidade como um estado e não como uma procurasem-fim. Eu queria lhes emprestar minha orelha e comunicarmo-nos um claro entendimento e apontarmo-nos uma luta que não fosse uma guerra suja entre nós. Eu queria um diálogo que extinguisse meu pânico e o medo \& ódio deles. (DANIEL, 1984, p. 51) 
É visando ao diálogo e por meio dele que a narrativa autobiograficcional de Herbert Daniel procura construir um campo exegético comprometido com a ruptura dos mecanismos de desigualdade, buscando gerar reciprocidade onde ela foi extirpada. Para promover esse diálogo é necessário um movimento tradutório que torne o corpo lócus da tradução ao se tornar eixo de abertura ao outro. Como diz Cláudia de Lima Costa - contagiada por Silviano Santiago (1978), Maria Lugones (1987), Mary Loise Pratt (1992) e Glória Anzaldúa (1987) - sobre a virada tradutória:

Se falar já implica traduzir e se a tradução é um processo de abertura à/ao outra/o, nele a identidade e a alteridade se misturam, tornando $\mathrm{o}$ ato tradutório um processo de des-locamento. $\mathrm{Na}$ tradução, há a obrigação moral e política de nos desenraizarmos, de vivermos, mesmo que temporariamente, sem teto para que a/o outra/o possa habitar, também provisoriamente, nossos lugares. Traduzir significa ir e vir ('worldtraveling para Lugones ["Playfulness, 'World'-Traveling"]), estar no entrelugar (Santiago), na zona de contato (Pratt), ou na fronteira (Anzaldúa Borderlands/La Frontera). Significa, enfim, existir sempre des-locada/o. (COSTA, 2012, p. 44)

Herbert Daniel afirma o seu corpo em território de deslocamento e, por meio de um esforço de escrita de si e do 
mundo, lança-se em suas memórias, ficções e fragmentos para possibilitar o diálogo como agente perpetrador e perpetuador da violência. Ao buscar desconstruir os mecanismos epistemológicos que engendram a própria violência, o livro Meu Corpo Daria um Romance se torna uma narrativa tradutória. A tradução precisa ser uma narrativa desarmada. O que é a armadura se não a imagem da necessidade de preservação de distinções de dentro e fora, do limite do eu e o outro, de uma metáfora da epistemologia da violência? A narrativa de Daniel busca romper as armações ideológicas das armaduras do conhecimento e do corpo.

Por isso, MEU CORPO DARIA UM ROMANCE é uma narrativa desarmada. Desarmado, como se diz de um espírito quando, avisado e municiado de sua capacitação deagir, abandona a armadura de conceitos recebidos. Desarmado com um jogo (totalmente diferente de um quebra-cabeça ou um brinquedo préfabricado) onde as peças não levam a nenhuma solução antes problematizada, mas onde os encaixes dos pedaços não têm regras certas ou erradas, e levam ao enigma que é a própria armação real do texto. Desarmado como a representação do mundo a partir dos dados aleatórios das apreensões de nossa percepção. (DANIEL, 1984, orelha) 


\section{A PATRIARQUÍVICA DA CONFISSÃO E DO TESTEMUNHO}

Jacques Derrida (2001) ao se debruçar sobre o tema do Arquivo, alertou para sua instauração em um poder patriarcal. Examinando o poder da "patriarquívica" (DERRIDA, 2001, p. 16), retomou na significação de arkhê que expressa ao mesmo tempo começo e comando - uma ordenação sequencial, ligada a um princípio histórico, e uma ordenação jússica, ligada a um princípio nomológico. Por trás do Arquivo e de seus mecanismos organizativos, há o poder patriarcal do Arconte. Derrida alerta que o poder do Arquivo não está somente em seu conteúdo, mas em sua constituição. Por isso, não basta enfrentar o poder do acesso, mas é preciso acima de tudo enfrentar o poder do princípio organizativo. Por esse motivo, há no arquivo um mal fundante que faz com que arquivar possa ser justamente apagar a memória. O tema do arquivo se conecta a Herbert Daniel, ao pensarmos como a sua escrita rememora exílios: o do desterro da militância clandestina no Brasil, a do asilo europeu em fuga da repressão militar brasileira e o degredo da homossexualidade. Daniel nunca foi aprisionado pelo aparato da ditadura. Perante o poder letal dos arcontes morais e militares, buscou constantemente escapar do testemunho e da confissão. 
No entanto, ao publicar sua primeira autobiografia em 1982, o Passagem para o próximo sonho, no ano seguinte ao voltar do exílio europeu ao Brasil, seu livro foi recebido por muitos como um testemunho: um depoimento de sua experiência da ditadura e uma confissão de sua homossexualidade. No ensaio "Os Sexo dos Anjos" de 1983, Herbert Daniel comenta essa recepção:

O mais divertido é que muita gente disse que eu "confessava" minha homossexualidade (ou meu pecado?). Acontece que consegui passar seis anos fugindo da polícia e nunca fui preso, nem torturado, para ser obrigado a confessar. Nem mesmo depor. Não seria agora que... Enfim, o que procuro? Diálogo (palavra que na tradução, com graça grega, seria a dialética). (DANIEL, 1983, p. 25)

Há no poder confessional a estruturação de um aparato repressor constitutivo da sexualidade. Nesse dispositivo, a ciência da sexualidade opera menos ao estabelecer censuras, do que ao construir o que investiga. "Muito menos do que proibir excessos do Corpo," - diz Daniel - "a Ciência forma um molejo, um jogo, uma linguagem padrão, com afirmações e as necessárias e decorrentes negações" (DANIEL, 1984, p. 27). Na Ditadura Militar, a tortura também virou método de produção de confissões, utilizando-as 
como principal mecanismo de produção da realidade ${ }^{5}$. A oposição entre quem obriga a depor e quem é obrigada a confessar é o resultado dessa patriarquívica. É perante os "hetero-investigadores" ou "heinterogoradores" (DANIEL, 1984, p. 26) que é produzido o homossexual - seja dentro de um ônibus na madrugada de Copacabana ou na recepção literária de uma obra. É diante do Arconte torturador, que somos obrigadas e obrigados a testemunhar.

Nesse contexto, a obra de Herbert Daniel não deve ser lida como uma Literatura de Testemunho - tal como a interpreta João Sinhori (2013). Não há, em Daniel, a intenção de testemunhar, seja compactuando com uma extorsão da intimidade ou buscando revelar o passado. Afinal, foi do testemunho que ele fugiu durante seis anos. Interpretá-la nessa chave de leitura é consignar sua vida ao Arquivo Militar Patriarcal ${ }^{6}$. Ao apresentar sua obra de 1982 de um "Romance Autocrítico", Daniel buscou justamente enfrentar os mecanismos do depoimento (exigência da

5 "Tortura sempre houve - e continua havendo: qualquer preso (comum) pode falar longamente das suas técnicas. O que caracteriza a nova fase que começa no final dos anos 60 e encontra seu apogeu em pleno milagre econômico é que a tortura deixou de ser simples recurso policial para ser erigida como 'método de investigação da realidade'. Um filosofia: cada filósofo tem um método de pesquisar a Verdade. A ditadura, filosoficamente, com seu método novo, não apenas investigava, como fazia a verdade, extorquida com rigor, paciência e sangue. O mais extraordinário é ver como os mecanismo jurídicos evoluíram para se adaptar a este novo sistema filosófico." (DANIEL, 1982, p. 39)

6 Em um contexto de luta pela memória e verdade, Derrida nos alerta que não basta lutar pela a abertura do Arquivos da Ditadura Militar Brasileira, é preciso, além do acesso, reivindicar a direito à participação na sua constituição e na sua interpretação, rompendo com a patriarquívica militar. 
ideologia dominante) e de um auto de defesa (contrapartida dessa mesma ideologia), por meio da produção de uma análise autocrítica.

Falar sobre a homossexualidade implica uma postura específica: ou se fala de um ponto de vista exterior ("científico"), ou se fala de dentro, isto é, como a homossexualidade fala. Neste segundo caso, pode-se gerar uma ideologia cheia de falseamentos, defensiva, explicativa etc. Tal ideologia é apenas a contrapartida da ideologia dominante. Por isso é importante uma crítica exatamente o contrário do depoimento, ou de um auto de defesa. Pelas características mesmas da sexualidade, o único discurso capaz de escapar das tramoias do Poder é uma análise autocrítica: falar da própria sexualidade (homo/hetero...?) sem aleamentos ou alienação. (DANIEL, 1983, p. 35-36)

Com esse escopo, a primeira pessoa nos textos de Daniel não é um sujeito que depõe, mas que expõe-se a partir de uma posição "excêntrica" (DANIEL, 1984, p. 26), que recusa qualquer mito da individualidade ou culto à personalidade, que são partes da filosofia do totalitarismo.

Não esse sujeito indiviso e central de um discurso, uma satisfeita consciência teórica, mas um dúbio autor que deixa escapar as manifestações do seu desejo, tentando ordenar suas duplicidades 
excêntricas. Falo do eu, como quem inventa com intencionalidade, para poder sustentar o diálogo com outras intencionalidades (as de vocês). (DANIEL, 1983, p. 26)

É visando ao escopo de sustentar o diálogo e desmontar a confissão ou testemunho - consignações da patriarquívica militar e da ciência da sexualidade - que Herbert Daniel abandona a noção de análise presente em seu romance de 1982 e em seu ensaio de 1983, para em 1984 construir uma narrativa desarmada. A recusa do método da análise, em nome das "fluições teóricas" é parte do projeto que se ancora - e a imagem da âncora não deve remeter ao pesado instrumento náutico que possibilita fixidez perante os movimentos do mar e sim a sua apropriação por comunidades homossexuais masculinas como insígnia da liberdade sexual que podia ser vivida nos movimentos dos navios em oposição à retidão da terra - na noção de diálogo e de contágio corporal para construir uma narrativa política e poética que enfrenta as distinções operadas pela violência homofóbica. Com o corpo apresentado como terreno tradutório, os heinterogoradores não encontram o confessor, mas a potência do inconfessável.

CONFESSO.

Mas nunca o que me exigem. Nunca!

Só o inconfessável.

(DANIEL, 1984, p. 118). 


\section{REFERÊNCIAS}

ANZÁLDUA, G. Borderlands/La Frontera: The New Mestiza. San Francisco: Aunt Lute Books, 1987.

BENJAMIN, W. Rua de mão única. 6ed. revista. São Paulo: Brasiliense, 2012.

COSTA, C. L. Feminismo e Tradução Cultura: Sobre a Colonialidade do Gênero e a Descolonização do Saber. Portuguese Cultural Studies 4, Fall, pp. 41-65, 2012.

DANIEL, H. Passagem para o próximo sonho. Rio de Janeiro: Codecri, 1982. . "Os Anjos do Sexo". In: DANIEL, H.; MICCOLIS, L. Jacarés \& Lobisomens: dois ensaios sobre a homossexualidade. Rio de Janeiro: Achiamé/Socci, pp. 13-68, 1983.

. Meu corpo Daria um Romance. Rio de Janeiro: Rocco, 1984. . Alegres e irresponsáveis abacaxis americanos. Rio de Janeiro:

Espaço Tempo, 1987.

DERRIDA, J. Mal de Arquivo: Uma Impressão Freudiana. Rio de Janeiro: Relume Dumará, 2001.

DOUGLAS, L. A. Two Loves. The Chameleon (1), 1894.

FOUCAULT, M. História da sexualidade 1 - A Vontade de Saber. Rio de Janeiro: Graal, 1988.

HARAWAY, D. "Saberes localizados: a questão da ciência para o feminismo e o privilégio da perspectiva parcial". In: Cadernos Pagu, São Paulo, n.5, pp. 07-42, 1995.

HARDING, S. The science question in feminism. Ithaca: Cornell Univ. Press, 1986.

HARDSTSOCK, N. "The feminist stand point: developing the ground for a specifically feminist historical materialism". In: HARDING, S. (Ed.) Feminism \& methodology. Bloogmington, Indiana: Indiana University Press, pp. 157180, 1986.

LUGONES, M. "Playfulness, 'World'-Traveling and Loving Perception." Hypatia 2.2. pp. 3-19, 1987. 
MIGNOLO, W. Histórias locais/projetos globais. Colonialidade, saberes subalternos e pensamento liminar. Belo Horizonte: Ed. UFMG, 2003.

PRATT, M. L. Imperial Eyes: Studies in Travel Writing and Transculturation. New York: Routledge, 1992.

SANTIAGO, S. "O entre-lugar do discurso latino-americano." In: Uma literatura nos trópicos. São Paulo: Editora Perspectiva, pp. 11-28, 1978.

SEDGWICK, E. K. Epistemology of the closet. Berkeley: University of California Press, 1990

. "A epistemologia do armário." In: Cadernos Pagu. Campinas, SP, v.28, Dossiê Sexualidades Disparatadas, pp. 19-54, 2007.

SINHORI, J. Narrativas armadas: a guerrilha urbana no testemunho de Alex Polari e Herbert Daniel. Dissertação (Mestrado em História Social). Programa de Pós-Graduação em História Social, Centro de Letras e Ciências Humanas, Universidade Estadual de Londrina, 2013.

WITTIG, M. The Straight Mind and other essays. Boston: Beacon Press, 1992.

Felipe Areda é mestrando do Programa de Pós-Graduação em Literatura da Universidade Federal de Santa Catarina. E-mail: felipe.areda@gmail.com 